\title{
Does preservation of the sub-valvular apparatus during mitral valve replacement affect long-term survival and quality of life? A Microsimulation Study
}

\author{
Christopher Rao1, Jonathan Hart ${ }^{1}$, Andre Chow ${ }^{1}$, Fotios Siannis ${ }^{3}$, \\ Polyxeni Tsalafouta1 ${ }^{1}$, Bari Murtuza ${ }^{1}$, Ara Darzi ${ }^{1}$, Frank C Wells ${ }^{2}$ and \\ Thanos Athanasiou*1
}

Address: ${ }^{1}$ Department Biosurgery and Surgical Technology, Imperial College London, London, UK, ${ }^{2}$ Department of Cardiothoracic Surgery, Papworth Hospital, Cambridge, UK and ${ }^{3}$ Medical Research Council Biostatistics Unit, Medical Research Council, Cambridge, UK

Email: Christopher Rao - christopher.rao@imperial.ac.uk; Jonathan Hart - jonathan.hart@imperial.ac.uk;

Andre Chow - andre.chow98@imperial.ac.uk; Fotios Siannis - fotios.siannis@mrc-bsu.cam.ac.uk;

Polyxeni Tsalafouta - p.athanasiou@ hotmail.co.uk; Bari Murtuza - bari.murtuza@imperial.ac.uk; Ara Darzi - a.darzi@imperial.ac.uk;

Frank C Wells - francis.wells@papworth.nhs.uk; Thanos Athanasiou* - tathan5253@aol.com

* Corresponding author

Published: 23 April 2008

Journal of Cardiothoracic Surgery 2008, 3:17 doi:10.1 186/1749-8090-3-17
Received: 18 January 2008

Accepted: 23 April 2008

This article is available from: http://www.cardiothoracicsurgery.org/content/3/1/17

(c) 2008 Rao et al; licensee BioMed Central Ltd.

This is an Open Access article distributed under the terms of the Creative Commons Attribution License (http://creativecommons.org/licenses/by/2.0), which permits unrestricted use, distribution, and reproduction in any medium, provided the original work is properly cited.

\begin{abstract}
Background: Techniques to preserve the sub-valvular apparatus in order to reduce morbidity and mortality following mitral valve replacement have been frequently reported. However, it is uncertain what impact sub-valvular apparatus preservation techniques have on long-term outcomes following mitral valve replacement. This study investigated the effect of sub-valvular apparatus preservation on long-term survival and quality of life following mitral valve replacement.
\end{abstract}

Methods: A microsimulation model was used to compare long-term survival and quality-adjusted life years following mitral valve replacement after conventional valve replacement and sub-valvular apparatus preservation. Probabilistic sensitivity analysis and alternative analysis were performed to investigate uncertainty associated with the results.

Results: Our Analysis suggests that patients survive longer if the sub-valvular apparatus are preserved (65.7\% SD 1.5\%, compared with $58.1 \%$ SD $1.6 \%$ at 10 years). The quality adjusted life years gained over a 10 year period where also greater after sub-valvular apparatus preservation. (6.54 QALY SD 0.07 QALY, compared with 5.6I QALY, SD 0.07 QALY). The superiority of preservation techniques was insensitive to patient age, parameter or model uncertainty.

Conclusion: This study suggests that long-term outcomes may be improved when the sub-valvular apparatus are preserved. Given the lack of empirical data further research is needed to investigate health-related quality of life after mitral valve replacement, and to establish whether outcomes differ between preservation techniques. 


\section{Background}

The optimum management of mitral valve insufficiency is valve repair [1]. Often valve replacement is necessary, however, as repair is impossible because of anatomical or aetiological considerations [2,3].

The first Mitral Valve Replacement (MVR) involved implantation of a Starr-Edwards prosthetic valve following complete excision of the mitral leaflets, chordae tendinae and the heads of the papillary muscles [4]. Initial experience with MVR was complicated by an increased incidence of low cardiac output syndrome and associated morbidity and mortality. Subsequently, several strategies were implemented to improve postoperative outcomes, including Sub-valvular Apparatus Preservation (SVP) [5].

The concept of SVP is more than 40 years old [6-8]. Despite the publication of several studies since the late1970 s suggesting that left ventricular function and mortality were improved following SVP, particularly in patients with mitral regurgitation, it is sometimes not undertaken [5,9-29]. Whilst technical considerations may limit adoption of SVP [30], surgical strategies to overcome these technical pitfalls have been discussed in the literature in some depth [5]. Arguably uncertainty about the long-term impact of SVP on patient-focused outcomes such as free of event survival and quality of life may be a factor.

Given the body of evidence suggesting that MVR is more effective with SVP, and that in many cases SVP was technically feasible [5] we felt it was important to quantify;

\section{What effect does SVP has on long-term survival?}

2. Does SVP affect long-term Health-Related Quality of Life (HRQOL)?

In order to address these questions we use a microsimulation model to combine recently published mortality data from the systematic review by Athanasiou et al [5], Government Actuarial Department Data on baseline population mortality [31], valve related mortality from the United Kingdom Heart Valve Registry (UKHVR) [32] and estimates of HRQoL from this study.

\section{Methods}

Markov microsimulation is a powerful tool that can be used to model morbidity and mortality following surgical interventions in the absence of empirical follow-up data $[33,34]$. It has been widely used in both general medical [35-38] and cardiothoracic journals [39-43] and is often a fundamental element of national technology assessment programmes [33,34,44-46]. It has previously been used to model outcomes following aortic valve replacement [4043].
In microsimulation it is assumed that a patient's HRQoL can be described by a finite number of states, and by modelling the transition between these states at the end of discrete time periods, called cycles, long term predictions can be made about HRQoL and survival.

\section{Microsimulation model}

An overview of our microsimulation model is shown in Figure 1. In our model we combine baseline mortality [31], with the mortality [32] and HRQoL associated with MVR in order to estimate long-term survival and QualityAdjusted Life Years (QALY). QALY are a product of the survival and HRQoL (or Utility) that a patient experiences over a defined time horizon.

The probability of moving between states at the end of each cycle was randomly drawn from assigned probability distributions (Table 1). Each microsimulation was repeated 1000 times to generate a "virtual" cohort of 1000 patients.

Analysis was performed over a 10 year time horizon, with one year cycles. Effects were discounted at 3.5\% and a range of $0-6 \%$ was used for sensitivity analysis according to National Institute of Health and Clinical Excellence (NICE), guidelines on health technology assessment [44]. The analysis was performed using decision analytical software (TreeAge-Pro TM, TreeAge, Williamstown, Massachusetts, USA).

We validated the model structure by comparing overall survival in the non-preservation group at 5 years, with empirical data obtained from the UKHVR [32]. We chose to use the UKHVR rather than data from randomised controlled trials as we felt it was important to ensure that the results of our study should be applicable to every-day cardiothoracic practice in the United Kingdom.

\section{Investigating uncertainty: probabilistic sensitivity analysis and alternative analysis}

There is an element of uncertainty associated with all attempts to consider long-term outcomes following surgical interventions. In Monte-Carlo simulation the modelling was repeated 1000 times for each cohort to generate probabilistic estimations of the combined effect of model parameter uncertainty [34].

Alternative analysis was performed to investigate the sensitivity of our results to patient age and the assumptions that we made about long-term valve-related mortality.

\section{Model parameters: survival data}

The microsimulation model combines population baseline mortality [31] with valve-related mortality [32] in 


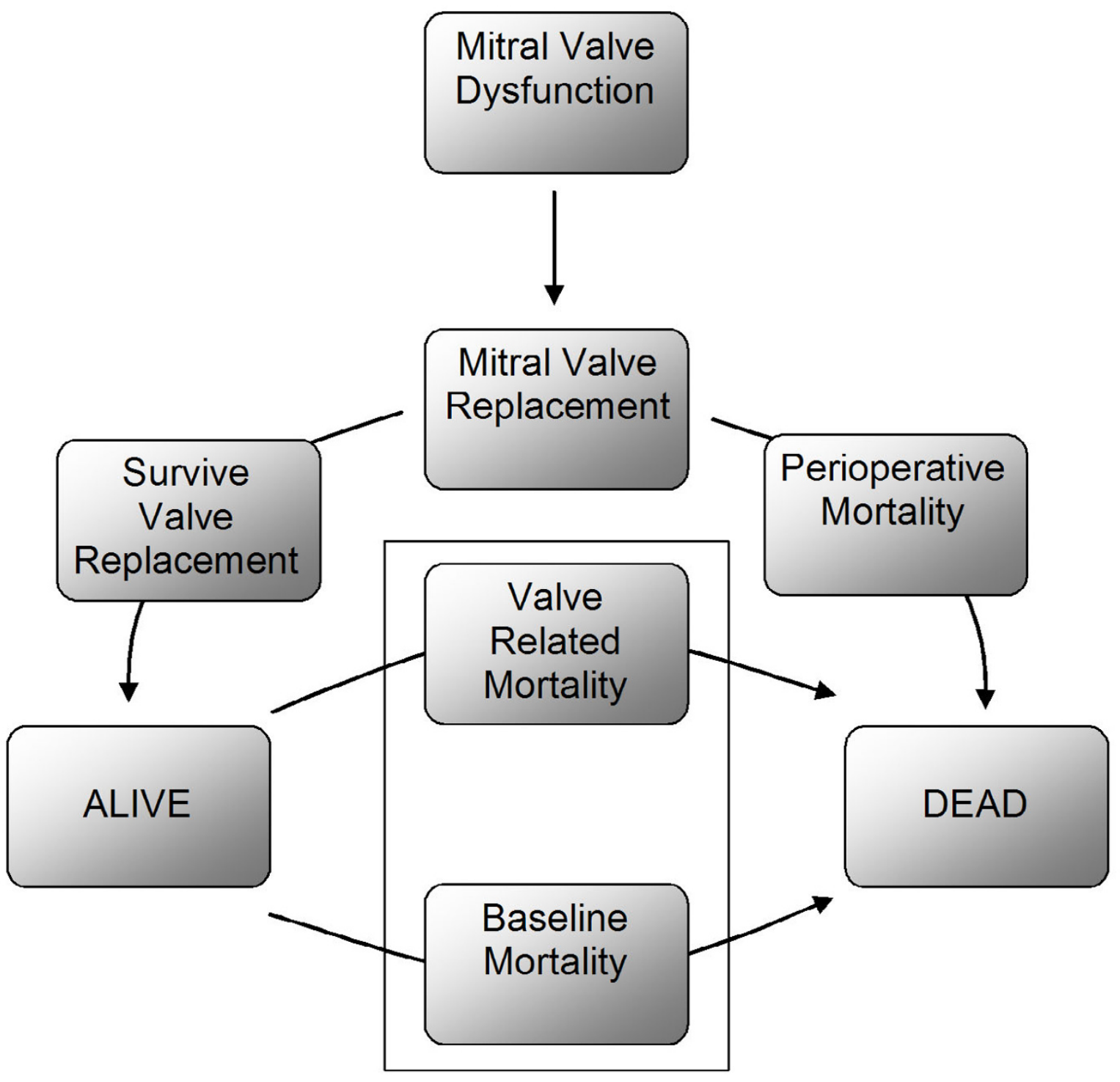

Figure I

Patients exist in either the "alive" or "dead" state. A patient can remain in either the "alive" state, or can move from the "alive" to the "dead" state at the end of each cycle. The probability of state transition is determined by valve-related mortality and baseline age and gender specific mortality. Whilst a patient exists in the "alive" state they accumulate an incremental utility payoff determined by the valve replacement technique used.

order to estimate overall survival for patients undergoing MVR.

The baseline population mortality was obtained from Government Actuarial Department (GAD) life tables [31] for a 62-year-old male cohort, as this is the mean age of patients undergoing mitral valve replacement in the United Kingdom [47].
Valve-related mortality for the non-preservation group was calculated by removing baseline population mortality from overall survival of the 14,148 patients recorded in the UKHVR who underwent MVR [32]. Valve-related mortality in the preservation group was calculated using estimates of valve-related mortality in the non-preservation group [32] and hazard ratios comparing preservation and non-preservation techniques. These hazard ratios were obtained from the meta-analysis of 2933 patients from 17 randomised and non-randomised studies by Athanasiou 
Table I: Summary of Model Parameters

\begin{tabular}{|c|c|c|c|c|c|}
\hline MODEL PARAMETER & VALUE & & RANGE/SD & & DISTRIBUTION \\
\hline Valve-Related Mortality Hazard Ratio I Year [5] & 0.1084 & 0.0782 & - & 0.2049 & Triangular \\
\hline Valve-Related Mortality Hazard Ratio 5 Year [5] & 0.0416 & 0.0197 & - & 0.0833 & Triangular \\
\hline \multicolumn{6}{|c|}{ Overall Survival without Preservation (62 year old cohort) [32] } \\
\hline Year I & $87.4 \%$ & & & & \\
\hline Year 2 & $84.3 \%$ & & & & \\
\hline Year 3 & $81.3 \%$ & & & & \\
\hline Year 4 & $77.5 \%$ & & & & \\
\hline Year 5 & $75.0 \%$ & & & & \\
\hline \multicolumn{6}{|c|}{ Overall Survival without Preservation (82 year old cohort) [32] } \\
\hline Year I & $79.8 \%$ & & & & \\
\hline Year 2 & $65.9 \%$ & & & & \\
\hline Year 3 & $64.1 \%$ & & & & \\
\hline Year 4 & $58.1 \%$ & & & & \\
\hline Year 5 & $40.7 \%$ & & & & \\
\hline Baseline Mortality [3I] & & & GAD Life Tables & & \\
\hline \multicolumn{6}{|l|}{ Postoperative Utility Without Preservation } \\
\hline Age $60-69$ & 0.6668 & & 0.1410 & & Normal \\
\hline Age 70-79 & 0.6292 & & 0.1330 & & Normal \\
\hline Age $80+$ & 0.6058 & & $0.128 \mid$ & & Normal \\
\hline \multicolumn{6}{|l|}{ Postoperative Utility With Preservation } \\
\hline Age $60-69$ & 0.7345 & & 0.0660 & & Normal \\
\hline Age 70-79 & 0.6931 & & 0.0622 & & Normal \\
\hline Age $80+$ & 0.6673 & & 0.0599 & & Normal \\
\hline Discount Rate [44] & 0.0350 & 0.0000 & - & 0.0600 & Triangular \\
\hline
\end{tabular}

et al [5] which reported hazard ratios at 1 and 5 years. Hazard ratios and confidence intervals for years 2, 3 and 4 where calculated using linear interpolation. After 5 years the valve-related hazard was assumed to remain constant. We recognise the limitations of this assumption, however because of limited data we were unable to do otherwise. To investigate the sensitivity of our results to this assumption we performed an alternative analysis in which we assumed that there was no valve-related mortality after year 5 .

As there is a trend to perform valve replacement in the United Kingdom in increasingly elderly patients [48] the effect of patient age on long-term outcomes following valve replacement was investigated in an 82 year old cohort using estimates of baseline mortality, obtained from GAD Life tables [31], and valve-related mortality obtained from in the same way as in the base case from the 86 patients aged over 80 who underwent MVR in the UKHVR [32].

\section{Model parameters: HRQoL}

As there are no published studies comparing HRQoL (utility) following conventional MVR and SAP, HRQoL following MVR was estimated using data on post-operative New York Heart Association (NYHA) class. 8 studies, including non-randomised studies, reported postoperative NYHA class [17-24]. Data was not used from 3 [22$24]$ as the study groups where not matched preoperatively according to NYHA class and consequently we could not ensure postoperative differences in NYHA class were due to a treatment effect.

In order to calculate the utility of patients in each of the cohorts (Table 1) we used published data on the utility decrement suffered by patients in each NYHA class [49], EuroQol [50] age-specific data for baseline utility in the United Kingdom, together with the number of patients in each NYHA class extracted from the included studies [1721]. Calculated age-specific utility values are shown in Table 2 together with data from the 677 patients used to calculate them.

\section{Results \\ Survival}

In the base case analysis 10-year survival was significantly improved following SAP $(65.7 \%$ SD $1.5 \%$, compared with $58.1 \%$ SD $1.6 \%$ at 10 years) with a difference in survival between conventional MVR and SAP of 7.6\% (SD 0.9\%) at 10 years (Figure 2). 5-year survival in the non-preservation group was $75.1 \%$ SD $1.4 \%$, not significantly different to the empirical estimates given by the UKHVR [32] $(73.8 \%)$, thus supporting the validity of our model structure.

\section{QALY}

Over a 10-year period the mean QALY payoff was 5.61 QALY, (SD 0.07 QALY), without SAP, and 6.54 QALY (SD 
Table 2: Utility Parameters used in the Model

\begin{tabular}{|c|c|c|c|c|c|c|c|c|c|c|c|c|c|c|c|c|}
\hline \multirow[b]{2}{*}{$\begin{array}{c}\text { NYHA } \\
\text { Class }\end{array}$} & \multicolumn{2}{|c|}{ Number of Patients [ $|7-2|]$} & \multirow{2}{*}{$\begin{array}{c}\% \text { Utility } \\
\text { Decrement } \\
{[49]}\end{array}$} & \multirow{2}{*}{$\begin{array}{l}\text { HRQoL } \\
\text { (Utility) }\end{array}$} & \multicolumn{2}{|c|}{ Age 30-39 } & \multicolumn{2}{|c|}{ Age $40-49$} & \multicolumn{2}{|c|}{ Age 50-59 } & \multicolumn{2}{|c|}{ Age 60-69 } & \multicolumn{2}{|c|}{ Age 70-79 } & \multicolumn{2}{|c|}{ Age 80+ } \\
\hline & $\begin{array}{c}\text { With } \\
\text { Preservation }\end{array}$ & $\begin{array}{c}\text { Without } \\
\text { Preservation }\end{array}$ & & & Mean & SD & Mean & SD & Mean & SD & Mean & SD & Mean & SD & Mean & SD \\
\hline 0 & 0 & 0 & 0.00 & & & & & & & & & & & & & \\
\hline 1 & 207 & 194 & 0.03 & $\begin{array}{c}\text { UK Baseline } \\
\text { [50] }\end{array}$ & 0.86 & & 0.85 & & 0.81 & & 0.80 & & 0.75 & & 0.73 & \\
\hline 2 & 74 & 126 & 0.20 & & & & & & & & & & & & & \\
\hline 3 & 5 & 47 & 0.35 & $\begin{array}{c}\text { With } \\
\text { Preservation }\end{array}$ & 0.79 & 0.07 & 0.78 & 0.07 & 0.75 & 0.07 & 0.73 & 0.07 & 0.69 & 0.06 & 0.67 & 0.06 \\
\hline \multirow[t]{2}{*}{4} & 0 & 24 & 0.70 & & & & & & & & & & & & & \\
\hline & & & & $\begin{array}{l}\text { Without } \\
\text { Preservation }\end{array}$ & 0.72 & 0.15 & 0.71 & 0.15 & 0.68 & 0.14 & 0.67 & 0.14 & 0.63 & 0.13 & 0.61 & 0.13 \\
\hline TOTA & 286 & 391 & & & & & & & & & & & & & & \\
\hline
\end{tabular}

0.07 QALY) with SAP. This represents an incremental QALY gain of 0.92 QALY (SD 0.04 QALY) for SAP compared with conventional MVR (Figure 3).

\section{Sensitivity analysis}

Probabilistic sensitivity analyses suggests that survival at 10 years is superior following SAP compared to conventional MVR with $100 \%$ certainty, and that the QALY payoff is superior with $86.3 \%$ certainty.

\section{Alternative analysis}

Absolute (15.4\% SD 1.1\% following SAP compared to $14.5 \%$ SD $1.1 \%$ following conventional repair) and incre- mental survival (0.09\% SD $0.03 \%)$ were predictably higher in the base case compared to the elderly patient cohort, given the higher baseline mortality in the more elderly cohort. Probabilistic sensitivity analysis still suggested that survival was superior following SAP with $100 \%$ certainty. In the elderly the QALY payoff was 4.29 QALY (0.07 QALY) in the preservation group and 3.76 QALY (0.08 QALY) in the conventional group. Probabilistic sensitivity analysis suggested that the QALY payoff was superior following SAP with $73.1 \%$ certainty.

Survival (69.4\% SD 1.5\% following SAP, compared to $64.5 \%$ SD $1.5 \%$ following conventional repair) and QALY

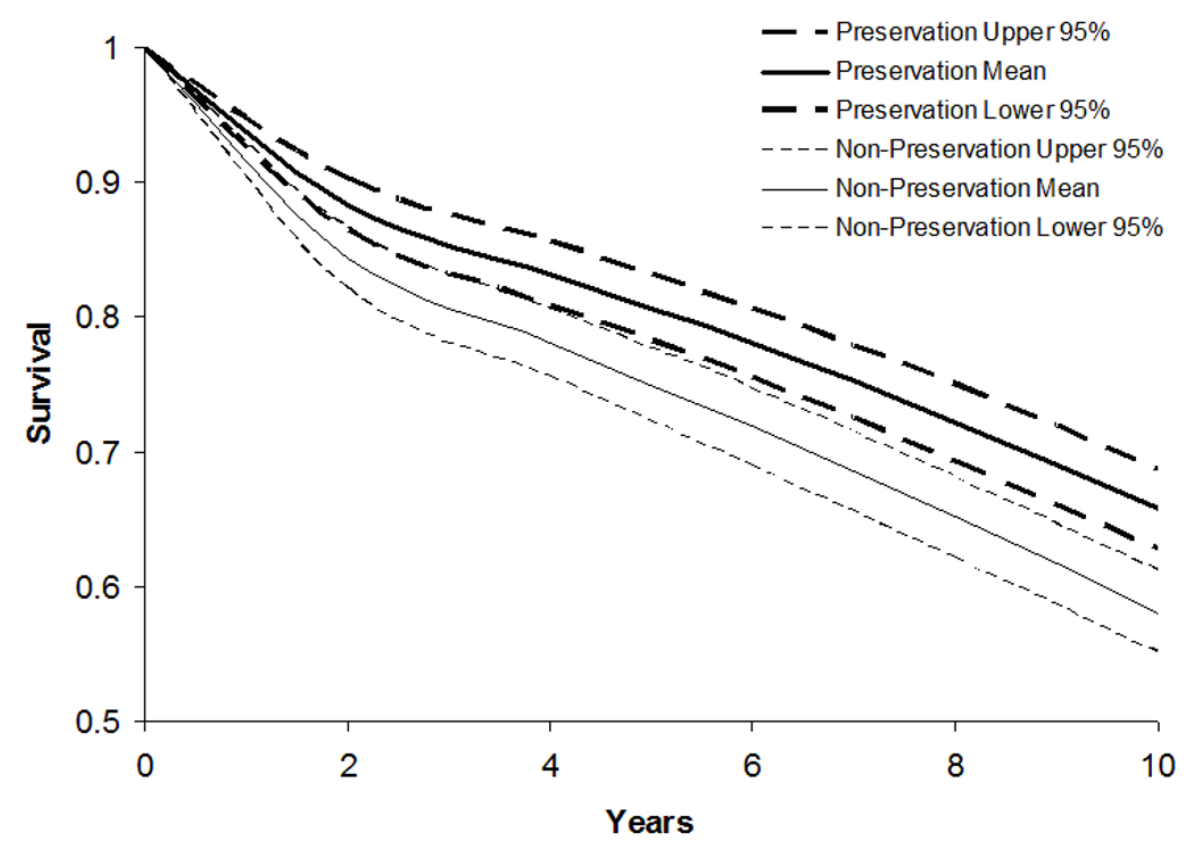

Figure 2

I0-year survival curves illustrating survival following SAP and conventional MVR. 


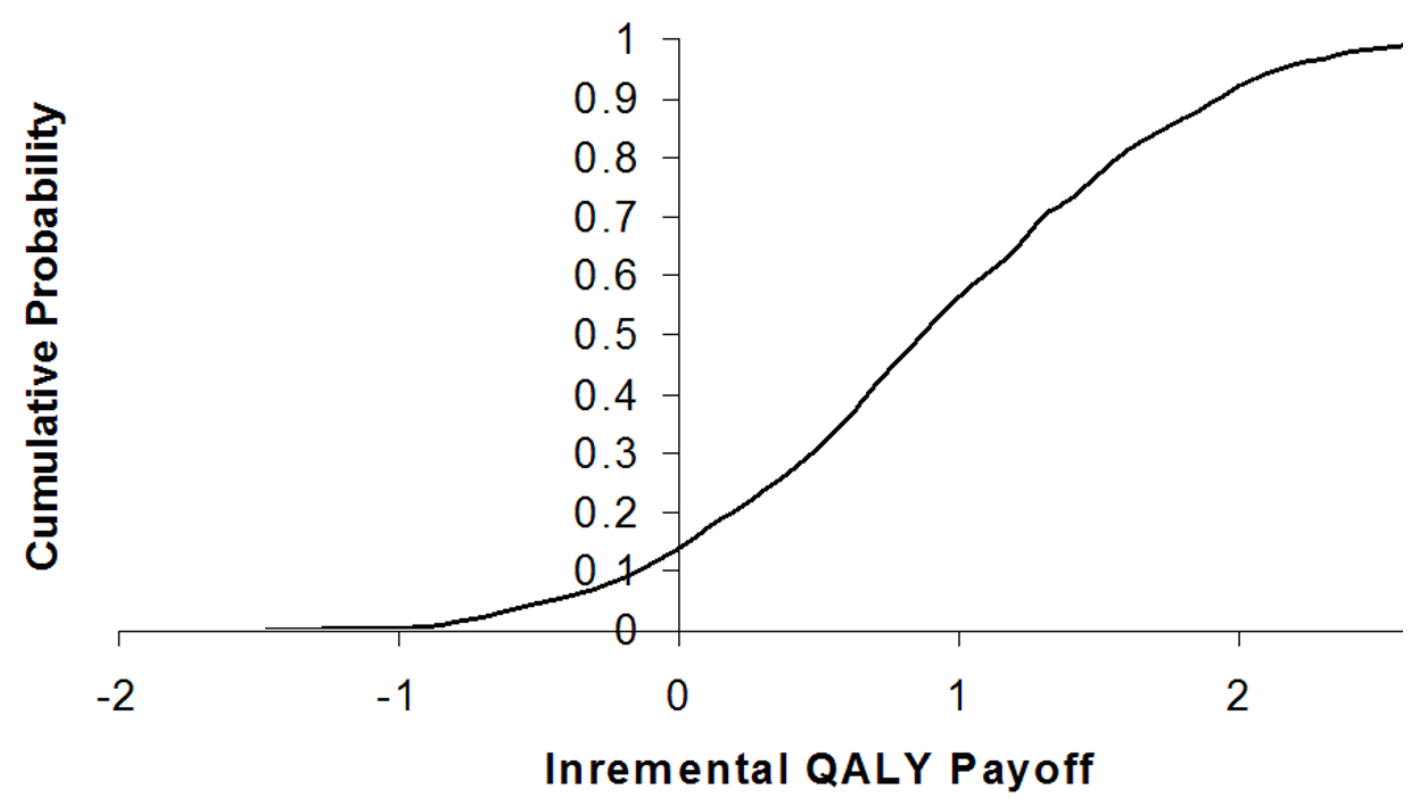

Figure 3

Cumulative probability distribution of incremental QALY payoffs for SAP compared to conventional MVR.

payoff (6.61 QALY, SD 0.07 QALY following SAP, compared to 5.72 QALY, SD 0.07 QALY following conventional repair) were higher in the alternative analysis compared to the base case. The incremental outcomes, however, were similar (4.9\% SD 0.7\%, 0.89 QALY SD 0.04 QALY), suggesting that our findings were not sensitive to the assumptions we made about valve-related mortality.

\section{Discussion}

Our results suggest that patients survive longer following MVR with SAP (65.7\% SD 1.5\%, compared with $58.1 \%$ SD $1.6 \%$ at 10 years). Whilst this represents a significant improvement in survival $(7.6 \% \mathrm{SD} 0.9 \%)$ it is entirely consistent with published empirical data, arguably even underestimating the benefits of SAP [25]. Our study also suggests that these improvements in survival remain significant irrespective of patient age. Furthermore, this study estimates long-term improvements in HRQoL following SAP, suggesting that in our base case there was an incremental QALY gain of 0.92 QALY (SD 0.04 QALY) over 10 years. Probabilistic sensitivity analysis and alternative analysis suggest that theses results are not sensitive to uncertainty associated with the model parameters, structure or patient age.

The main cause of death after MVR is myocardial failure [51]. Several animal and human echocardiographic physiological studies have shown better maintenance of left ventricular function following SAP [6-8,51-55]. It is suggested that this is because papillary muscles are important to left ventricular contraction as they draw the mitral ring toward the apex, causing shortening of the long axis and spherity of the chamber, thereby contributing to better ejection of blood [56]. Despite existing evidence suggesting that SAP reduces morbidity and mortality [9-17] the sub-valvular apparatus is not always preserved often because it is not possible to preserve them. It is argued that the preserved sub-valvular apparatus prevent an adequately sized prosthetic valve from being used, and cause left ventricular outflow tract obstruction, by interfering with prosthetic valve function [26,57-60]. Whilst techniques to eliminate outflow tract obstruction following sub-valvular apparatus preservation have been described [27], it is reported that some of the preservation techniques cause alteration of the left ventricular geometry, causing rupture of the papillary muscles, systemic embolization and dehiscence of the mitral leaflets from their transposed positions as well as increasing ischemic time [26,56-60]. Finally SAP is often not technically possible because of active endocarditis, anatomical or pathophysiological considerations $[5,28,61]$.

However, despite these concerns the evidence is clear. This study suggests that HRQoL is improved following SAP. It supports previously published data sets and meta-analytical data [5] which demonstrate that survival is significantly improved following SAP and represents further 
evidence that when technically feasible SAP should be routinely performed.

\section{Study limitations}

The findings of our microsimulation are weakened by a lack of empirical data, particularly randomised data, in several important areas. Firstly, in this study HRQoL was calculated from the surrogate outcome, NYHA heart failure class because no empirical data was available on the association between SAP and HRQoL. Whilst NYHA has been shown to be associated with HRQoL [49], this methodology has not been validated in patients after MVR. Furthermore, we made the assumption that NYHA class remained constant during the follow-up period, and only accounted for differing mortality in different NYHA classes indirectly through the higher mortality in patients in the conventional MVR group who also tended to have worse NYHA function. Finally in many cases we relied on data from non-randomised sources to populate our model as high-quality, relevant randomised data was not available.

We did not consider the effect of re-intervention because of the dependence of valve-life on the type of prosthesis used, and limited information on the rates of redo-MVR following different techniques. This is an important limitation as outcomes are worse following re-intervention [28]. We feel that its impact on our results, however, was minimal as the mortality associated with early valve failure and subsequent re-intervention has been accounted for in the valve-related mortality, and the time horizon of our analysis was limited to 10 years.

There are more general weaknesses associated with decision analytical techniques such as microsimulation, for example, an increasing tendency to accumulate modelling error as the time horizon increases, and a tendency to overly formalise or simplify problems $[33,34]$. We minimised the impact of accumulated modelling error by limiting our analysis to a 10-year horizon, and validated our model structure using empirical data.

Finally, because of an absence of empirical data on longterm HRQoL and survival we were unable to consider the relative efficacy of different SAP techniques, in particular bi-leaflet preservation. This is important as there is relevant evidence from randomised controlled trials, that bileaflet preservation may result in superior outcomes compared to other partial preservation techniques $[29,62]$.

\section{Conclusion}

Despite the assumptions that we where forced to make in our analysis because of insufficient data, this study supports previous evidence of the superior efficacy of SAP compared to conventional MVR. We have quantified ben- efits in both survival and QALY following SAP, and shown these results to be insensitive to uncertainty about model parameters or structure. Whilst further research clearly needs to be conducted to establish whether complete SAP further improves results, this study suggest that SAP may improve survival and HRQoL following MVR.

\section{Abbreviations}

GAD: Government Actuary's Department; HRQoL: Health Related Quality of Life; MVR: Mitral Valve Replacement; NICE: National Institute of Health and Clinical Excellence; NYHA: New York Heart Association; QALY: Quality Adjusted Life Years; SD: Standard Deviation: SVP: Sub-valvular Apparatus Preservation; UKHVR: United Kingdom Heart Valve Register.

\section{Authors' contributions}

CR was responsible for study design, statistical analysis, data interpretation, and manuscript drafting. JH and AC were responsible for manuscript drafting, critical editing and revision for important intellectual content. PT and BM were responsible for data collection, data extraction analysis and interpretation. FS was responsible for data extraction analysis and critical statistical analysis. AD and FCW were responsible for providing important intellectual content throughout the manuscript's production and for final approval of the version to be published. TA is the guarantor for this paper and accepts full responsibility for the work and/or the conduct of the study. His involvement was critical to every phase of this work. He had access to the data, and controlled the decision to publish. All authors read and approved the final manuscript.

\section{References}

I. Shuhaiber J, Anderson RJ: Meta-analysis of clinical outcomes following surgical mitral valve repair or replacement. Eur J Cardiothorac Surg 2007, 3 I:267-275.

2. Yau TM, El-Ghoneimi YA, Armstrong S, Ivanov J, David TE: Mitral valve repair and replacement for rheumatic disease. J Thorac Cardiovasc Surg 2000, 1 1 9:53-60.

3. Grossi EA, Galloway AC, Miller JS, Ribakove GH, Culliford AT, Esposito R, Delianides J, Buttenheim PM, Baumann FG, Spencer FC, Colvin $S B$ : Valve repair versus replacement for mitral insufficiency: when is a mechanical valve still indicated? J Thorac Cardiovasc Surg 1998, I I 5:389-394. discussion 394-386

4. Starr A, Edwards ML: Mitral replacement: clinical experience with a ball-valve prosthesis. Ann Surg 196I, 154:726-740.

5. Athanasiou T, Chow A, Rao C, Aziz O, Siannis F, Ali A, Darzi A, Wells F: Preservation of the mitral valve apparatus: evidence synthesis and critical reappraisal of surgical techniques. Eur J Cardiothorac Surg 2008:391-40I.

6. Lillehei CW: Value of Preserving Chordal Integrity. Both experimental and clinical data (Discussion). J Thorac Cardiovasc Surg 1963, 46:494-495.

7. Lillehei CW: Complete mitral valve replacement preserving papillary muscle-chordae tendinae-annulus continuity (Abstract). Circulation 1963, 28:757.

8. Lillehei CW, Levy MJ, Bonnabeau RC Jr: Mitral Valve Replacement with Preservation of Papillary Muscles and Chordae Tendineae. J Thorac Cardiovasc Surg 1964, 47:532-543.

9. Miller DW Jr, Johnson DD, Ivey TD: Does preservation of the posterior chordae tendineae enhance survival during mitral valve replacement? Ann Thorac Surg 1979, 28:22-27. 
10. David TE, Strauss HD, Mesher E, Anderson MJ, Macdonald IL, Buda AJ: Is it important to preserve the chordae tendinae and papillary muscles during mitral valve replacement? Can J Surg I98I, 24:236-239.

II. David TE, Burns RJ, Bacchus CM, Druck MN: Mitral valve replacement for mitral regurgitation with and without preservation of chordae tendineae. J Thorac Cardiovasc Surg 1984, 88:7|8-725.

12. David TE, Uden DE, Strauss HD: The importance of the mitral apparatus in left ventricular function after correction of mitral regurgitation. Circulation 1983, 68:1176-82.

13. David TE, Ho WC: The effect of preservation of chordae tendineae on mitral valve replacement for postinfarction mitral regurgitation. Circulation 1986, 74: II 16-120.

14. Hetzer R, Bougioukas G, Franz M, Borst HG: Mitral valve replacement with preservation of papillary muscles and chordae tendineae - revival of a seemingly forgotten concept. I. Preliminary clinical report. Thorac Cardiovasc Surg 1983, 3 I:291-296.

I5. Hetzer R, Drews T, Siniawski H, Komoda T, Hofmeister J, Weng Y: Preservation of papillary muscles and chordae during mitral valve replacement: possibilities and limitations. J Heart Valve Dis 1995, 4(Suppl 2):SII5-I 23.

16. Dottori V, Barberis L, Lijoi A, Giambuzzi M, Maccario M, Faveto C: Initial experience of mitral valve replacement with total preservation of both valve leaflets. Tex Heart Inst J 1994, 2I:215-219.

17. Dubiel TW, Borowiec JW, Mannting F, Landelius J, Hansson HE, Nystrom SO, Cadavid E: Mitral valve prosthetic implantation with preservation of native mitral valve apparatus. Scand J Thorac Cardiovasc Surg 1994, 28: I I5-121.

18. Muthialu N, Varma SK, Ramanathan S, Padmanabhan C, Rao KM, Srinivasan $M$ : Effect of chordal preservation on left ventricular function. Asian Cardiovasc Thorac Ann 2005, 13:233-237.

19. Cingoz F, Gunay C, Kuralay E, Yildirim V, Kilic S, Demirkilic U, Arslan $M$, Tatar $H$ : Both leaflet preservation during mitral valve replacement: modified anterior leaflet preservation technique. J Card Surg 2004, 19:528-534.

20. Dilip D, Chandra A, Rajashekhar D, Padmanabhan M: Early beneficial effect of preservation of papillo-annular continuity in mitral valve replacement on left ventricular function. J Heart Valve Dis 200I, I 0:294-300. discussion 300-291

21. Kirali K, Tuncer A, Uyar I, Mansuroglu D, Daglar B, Ipek G, Isik O, Yakut C: Is posterior leaflet preservation in the surgical treatment of rheumatic mitral insufficiency without left ventricular dysfunction necessary? Cardiovasc Surg 200I, 9:58-63.

22. Straub UJ, Huwer H, Petzold T, Kalweit G, Volkmer I, Gams E: Preservation of the mitral sub-valvular apparatus in multiple valve procedures. J Heart Valve Dis 1995, 4:477-483.

23. Hennein HA, Swain JA, Mclntosh CL, Bonow RO, Stone CD, Clark $R E$ : Comparative assessment of chordal preservation versus chordal resection during mitral valve replacement. J Thorac Cardiovasc Surg 1990, 99:828-836. discussion 836-827

24. Goor DA, Mohr R, Lavee J, Serraf A, Smolinsky A: Preservation of the posterior leaflet during mechanical valve replacement for ischemic mitral regurgitation and complete myocardial revascularization. J Thorac Cardiovasc Surg 1988, 96:253-260.

25. David TE, Armstrong S, Sun Z: Left ventricular function after mitral valve surgery. J Heart Valve Dis 1995, 4(Suppl 2):SI75-I80.

26. Cohn LH, Reis RL, Morrow AG: Left ventricular function after mitral valve replacement. Comparative studies following resection or preservation of chordae tendineae. J Thorac Cardiovasc Surg 1968, 56: I I-15.

27. Reardon MJ, David TE: Mitral valve replacement with preservation of the sub-valvular apparatus. Curr Opin Cardiol 1999, 14:104-II0.

28. Borger MA, Yau TM, Rao V, Scully HE, David TE: Reoperative mitral valve replacement: importance of preservation of the sub-valvular apparatus. Ann Thorac Surg 2002, 74: |482-| 487.

29. Chowdhury UK, Kumar AS, Airan B, Mittal D, Subramaniam KG, Prakash R, Seth S, Singh R, Venugopal P: Mitral valve replacement with and without chordal preservation in a rheumatic population: serial echocardiographic assessment of left ventricular size and function. Ann Thorac Surg 2005, 79:1926-33.

30. Sasaki H, lhashi K: Chordal-sparing mitral valve replacement: pitfalls and techniques to prevent complications. Eur J Cardiothorac Surg 2003, 24:650-652.
31. The United Kingdom Governement Actuary's Department (GAD) Interim Life Tables 2003-5 [http://www.gad.gov.uk]

32. Asimakopoulos G, Edwards M-B, Brannan J, Taylor KM: Survival and cause of death after mitral valve replacement in patients aged 80 years and over: Collective results from the UK heart valve registry. Eur / Cardiothorac Surg 1997, I I:922-928.

33. Drummond MF, Sculpher MJ, Torrance GW, O'Brien BJ, Stoddart GL: Methods for the Economic Evaluation of Health Care Programmes Oxford, Oxford University Press; 2004.

34. Briggs A, Claxton K, Sculpher M: Decision Modelling for Health Economic Evaluation Oxford, Oxford University Press; 2006.

35. Lubitz J, Cai L, Kramarow E, Lentzner H: Health, Life Expectancy, and Health Care Spending among the Elderly. NEJM 2003, 349: 1048-1055

36. Schousboe JT, Taylor BC, Fink HA, Kane RL, Cummings SR, Orwoll ES, Melton JL III, Bauer DC, Ensrud KE: Cost-effectiveness of Bone Densitometry Followed by Treatment of Osteoporosis in Older Men. JAMA 2007, 298:629-637.

37. Lim SS, Gaziano TA, Gakidou E, Reddy KS, Farzadfar F, Lozano R, Rodgers A: Prevention of cardiovascular disease in high-risk individuals in low-income and middle-income countries: health effects and costs. The Lancet 2007, 370(9604):2054-2062.

38. Rao C, Aziz O, Panesar SS, Jones C, Morris S, Darzi A, Athanasiou T: Cost effectiveness analysis of minimally invasive internal thoracic artery bypass versus percutaneous revascularisation for isolated lesions of the left anterior descending artery. BMJ 2007, 334:62I-7.

39. Rao C, De Lisle Stanbridge R, Chikwe J, Pepper J, Skapinakis P, Aziz O, Darzi A, Athanasiou T: Does Previous Percutaneous Coronary Stenting Compromise the Long-Term Efficacy of Subsequent Coronary Artery Bypass Surgery? A Microsimulation Study. Ann Thorac Surg 2008, 85:50I-7.

40. Puvimanasinghe JP, Takkenberg JJ, Edwards MB, Eijkemans MJ, Steyerberg EW, Van Herwerden LA, Taylor KM, Grunkemeier GL, Habbema JD, Bogers AJ: Comparison of outcomes after aortic valve replacement with a mechanical valve or a bioprosthesis using microsimulation. Heart 2004, 90: I I72-I I78.

4I. Puvimanasinghe JP, Takkenberg JJ, Eijkemans MJ, Steyerberg EW, van Herwerden LA, Grunkemeier GL, Habbema JD, Bogers AI: Choice of a mechanical valve or a bioprosthesis for AVR: does CABG matter? Eur J Cardiothorac Surg 2003, 23:688-695. discussion 695

42. Puvimanasinghe JP, Takkenberg JJ, Eijkemans MJ, van Herwerden LA, Jamieson WR, Grunkemeier GL, Habbema JD, Bogers AJ: Comparison of Carpentier-Edwards pericardial and supraannular bioprostheses in aortic valve replacement. Eur J Cardiothorac Surg 2006, 29:374-379.

43. Puvimanasinghe JP, Takkenberg JJ, Eijkemans MJ, Steyerberg EW, van Herwerden LA, Grunkemeier GL, Habbema JD, Bogers AJ: Prognosis after aortic valve replacement with the CarpentierEdwards pericardial valve: use of microsimulation. Ann Thorac Surg 2005, 80:825-831.

44. National Institute for Health Clinical Excellence (NICE): Guide to the Methods of Technology Appraisal London, NICE; 2004.

45. Reeves BC, Angelini GD, Bryan AJ, Taylor FC, Cripps T, Spyt TJ, Samani NJ, Roberts JA, Jacklin P, Seehra HK, Culliford LA, Keenan DJM, Rowlands DJ, Clarke B, Stanbridge R, Foale R: A multi-centre randomised controlled trial of minimally invasive direct coronary bypass grafting versus percutaneous transluminal coronary angioplasty with stenting for proximal stenosis of the left anterior descending coronary artery. Health Technol Assess 2004, 8: I-43.

46. National Institute for Health Clinical Excellence (NICE): Statins for the prevention of cardiovascular events London, NICE; 2006.

47. Society of Cardiothoracic Surgery in Great Britain and Ireland (SCTS): National Adult Cardiac Surgical Database Report 2000 - 2001 Henleyon-Thames, Dendrite Clinical Systems; 2002.

48. Taylor K: The United Kingdom Heart Valve Registry: the first 10 years. Heart 1997, 77:295-296.

49. Lewis EF, Johnson PA, Johnson W, Collins C, Griffin L, Stevenson LW: Preferences for quality of life or survival expressed by patients with heart failure. J Heart Lung Transplant 200I, 20:1016-1024.

50. Szende A, Williams A: Measuring self-reported population health: an international perspective based on EQ-5D Rotterdam, EuroQol group; 2004. 
5I. Yun KL, Rayhill SC, Niczyporuk MA, Fann JI, Zipkin RE, Derby GC, Handen CE, Daughters GT, Ingels NB Jr, Bolger AF, et al.: Mitral valve replacement in dilated canine hearts with chronic mitral regurgitation. Importance of the mitral sub-valvular apparatus. Circulation I991, 84:IIII I 2-I 24.

52. Okita $Y$, Miki S, Ueda Y, Tahata T, Sakai T: Left ventricular function after mitral valve replacement with or without chordal preservation. J Heart Valve Dis 1995, 4:S I8I-92.

53. Yagyu K, Matsumoto H, Asano K: Importance of the mitral complex in left ventricular contraction - an analysis of the results of mitral valve replacement with preservation of the posterior mitral complex. Thorac Cardiovasc Surg 1987, 35:166-7I.

54. Ghosh PK, Shah S, Das A, Chandra M, Agarwal SK, Mittal PK: Early evidence of beneficial effects of chordal preservation in mitral valve replacement on left ventricular dimensions. Eur J Cardiothorac Surg 1992, 6:655-9.

55. Rozich JD, Carabello BA, Usher BW, Kratz JM, Bell AE, Zile MR: Mitral valve replacement with and without chordal preservation in patients with chronic mitral regurgitation. Mechanisms for differences in postoperative ejection performance. Circulation 1992, 86:1718-26.

56. Talwar S, Jayanthkumar HV, Kumar AS: Chordal Preservation during mitral valve replacement: basis, techniques and results. IJTCVS 2005, $21: 45-52$.

57. Bjoerk VO, Bjoerk L, Malers E: Left Ventricular Function after Resection of the Papillary Muscles in Patients with Total Mitral Valve Replacement. J Thorac Cardiovasc Surg 1964, 48:635-639.

58. Kirklin JW: Replacement of the mitral valve for mitral incompetence. Surgery 1972, 72:827-836.

59. Rastelli GC, Tsakiris AG, Banchero N, Wood EH, Kirklin JW: Cardiac performance after replacement of the dog mitral valve with Starr-Edwards prosthesis with and without preservation of the chordae tendineae. Surg Forum 1966, 17:178-179.

60. Rastelli GC, Tsakiris AG, Frye RL, Kirklin JW: Exercise tolerance and hemodynamic studies after replacement of canine mitral valve with and without preservation of chordae tendineae. Circulation 1967, 35:134-41.

61. Aagaard J, Andersen UL, Lerbjerg G, Andersen LI: Expanding the use of total mitral valve preservation in combination with implantation of the CarboMedics heart valve prosthesis. J Cardiovasc Surg 1999, 40(2): I77-8I.

62. Yun KL, Sintek CF, Miller DC, Pfeffer TA, Kochamba GS, Khonsari S, Zile MR: Randomized trial comparing partial versus complete chordal-sparing mitral valve replacement: effects on left ventricular volume and function. J Thorac Cardiovasc Surg 2002, | 23:707-|4.

\section{Publish with Bio Med Central and every scientist can read your work free of charge}

"BioMed Central will be the most significant development for disseminating the results of biomedical research in our lifetime. "

Sir Paul Nurse, Cancer Research UK

Your research papers will be:

- available free of charge to the entire biomedical community

- peer reviewed and published immediately upon acceptance

- cited in PubMed and archived on PubMed Central

- yours - you keep the copyright

Submit your manuscript here:

http://www.biomedcentral.com/info/publishing_adv.asp
BioMedcentral 